Faculdade de Ciências da Educação e Saúde - FACES

Curso de Psicologia

As experiências de ser cuidador:

Uma análise de processos subjetivos individuais e sociais

Gustavo Andrade-Jesus

Brasília

2018 
Faculdade de Ciências da Educação e Saúde - FACES

Curso de Psicologia

A experiência de ser cuidador:

Uma análise de processos subjetivos individuais e sociais

\section{Gustavo Andrade-Jesus}

Relatório final de pesquisa de Iniciação Científica apresentado à Assessoria de Pós-Graduação e Pesquisa do Centro Universitário de Brasília UniCEUB pela Faculdade de Ciências da Educação e Saúde - FACES.

Orientadora: Dra. Valéria Deusdará Mori.

Brasília 
Se pudermos nos colocar no que há de mais genuíno em nossa condição humana, poderemos testemunhar o processo resiliente do ser humano, mesmo em face de violência, horror e experiências traumáticas. Se pudermos tolerar nossos sentimentos e nossas respostas contratransferênciais, acompanharemos essa pessoa em seu processo de restauração de significado e de propósito diante da vida, para além do sofrimento

Ana Lúcia Toledo, Cristina Prizanteli, Karina Polido, Maria Helena Franco e Sandra Santos, 2015 


\section{Resumo}

O cuidar se constitui como um dos exercícios mais antigos e fundamentais para a existência do ser humano. Assim, as práticas de cuidado podem ser compreendidas como uma necessidade e recurso do ser humano que perpassa as esferas biológicas, psicológicas, espirituais, antropológicas, socioculturais e ecológicas auxiliando assim na promoção, proteção, recuperação, e desenvolvimento diante da criação de novas configurações de relações nos cenários de agravos à saúde. Sendo um fenômeno complexo e abarcando produções individuais e coletivas o cuidado pode ser uma prática de caráter formal/profissional e informal/popular. Logo, cuidar de outra pessoa é um processo de troca de experiências, muitas vezes dolorosas, onde o cuidador entra em contato direto com o modo de ser, de viver do outro e de estar no mundo de uma pessoa, convivendo quase que diariamente com os medos, angustias e sofrimentos físicos e não físicos dessa pessoa. O convívio quase que diário com o sofrimento do outro implica em se relacionar com quem sofre, identificar-se e sentir-se parte do processo de adoecimento. Destaca-se nesse ponto que é impossível conviver com o sofrimento do outro e sair sem nenhum impacto/produção físico e/ou subjetivo, visto que a experiência de cuidar envolve a pessoa que é cuidada e quem cuida. Diante da problemática apresentada o estudo teve como objetivo compreender os processos subjetivos individuais e sociais na perspectiva de quem cuida. A construção das informações se deu através do método construtivointerpretativo assentado na Epistemologia Qualitativa proposto por González Rey que considera como elementos centrais: o conhecimento como produção humana, a legitimação do singular e o processo de dialogicidade. Participou do estudo uma mulher de 45 anos, casada, com filhos e cuidadora do companheiro diagnosticado com esquizofrenia e o instrumento utilizado foi a dinâmica conversacional, por viabilizar o processo comunicacional. A guisa de conclusões possibilitou a compreensão de que o exercício do cuidado ainda é um processo quase que exclusivamente feminino, doravante, o atual cenário histórico-cultural tem atribuído à mulher novas funções na sociedade, sendo possível pensar o feminino ocupando cargos para além dos domésticos. No entanto, o cuidado vem como ponto conflituoso nesse, visto que exige da mulher em determinadas situações a (re)dedicação exclusiva ao ambiente doméstico ou ocupar outras funções e também, cuidar, o que pode acarretar sobrecarga e potencializa a viabilidade de adoecimentos somáticos e psicológicos em cuidadoras.

Palavras-Chave: Processos Subjetivos. Adoecimento. Cuidados em Saúde Mental. 


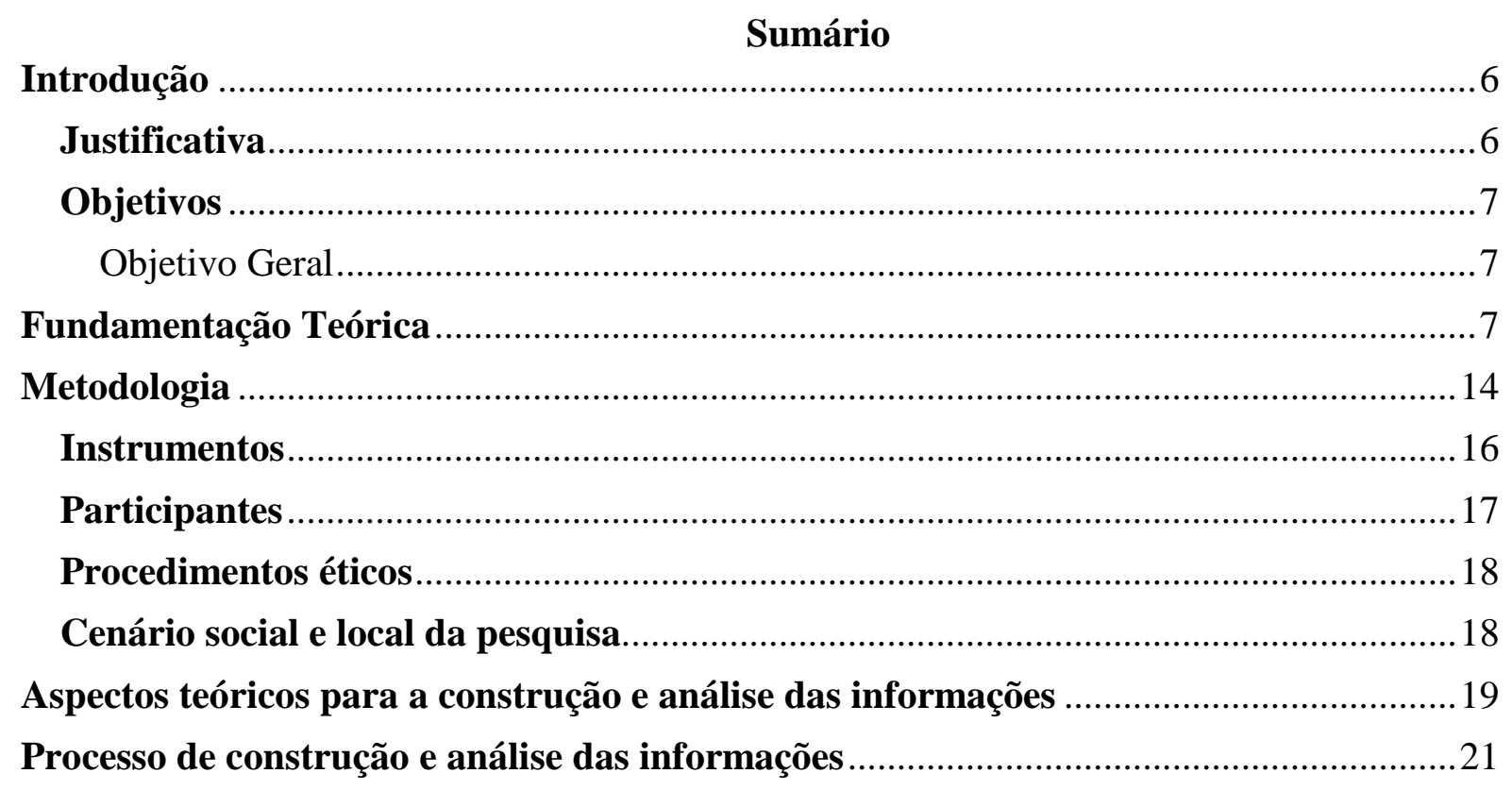




\section{Introdução}

Esse trabalho se propõe a discutir como se configuram os diferentes processos subjetivos de cuidadores na relação de cuidado com o outro e forma como aspectos subjetivos individuais e sociais tomam forma nesse percurso.

Para a compreensão desses processos nos basearemos na teoria da subjetividade proposta por González Rey (2005a). Entendemos que no processo de cuidado tanto quem é cuidado como quem é cuidador passam por experiências que geram para ambos efeitos diversos com desdobramentos tanto individuais, relacionais e sociais. O processo de cuidado envolve relacionar-se com outro de forma mais próxima para atender suas necessidades.

Muitas vezes, esse processo implica demandas que geram tensões nos relacionamentos e possuem potencialidade de emocionar e gerar conteúdos subjetivos na díade cuidador-quem é cuidado, o que fará que cada relação se construa de forma única e singular.

Para esse estudo o método utilizado será o construtivo interpretativo com base na epistemologia qualitativa de González Rey (2005b). Os instrumentos utilizados serão o formulário de caracterização de participante, o conflito de diálogos e o complemento de frases. E, os participantes serão 3 cuidadores independente do gênero e que tenham exercido a função de cuidador.

\section{Justificativa}

Compreender os aspectos subjetivos da experiência do cuidador pode auxiliar na organização de estratégias de promoção de saúde deste grupo já que hoje a literatura científica e o relato de profissionais e até mesmo dos cuidadores apontam para possíveis adoecimentos advindos dos processos de cuidado.

Diferentes pesquisas podem evidenciar processos que se ocultam nos discursos sobre cuidado e estão dissociados da experiência das pessoas que cotidianamente 
vivenciam as demandas desse tipo de relacionamento.

\section{Objetivos}

\section{Objetivo Geral}

Compreender os processos subjetivos individuais e sociais na perspectiva de quem cuida

\section{Objetivos Específicos}

1. Compreender discursos e representações que permeiam a experiência do cuidado;

2. Discutir os desdobramentos subjetivos individuais do cuidador e o processo de cuidar.

\section{Fundamentação Teórica}

O cuidado está presente nas nossas vidas desde muito cedo. Tal que Mori e Cavalcanti (2017) cuidar é uma prática antiga histórica e culturalmente estabelecida, onde a relação de cuidado tem ligação com a sobrevivência da espécie. Desde os momentos iniciais da nossa vida temos exemplos de histórias e vivências de cuidado vindas do seio da nossa família.

Segundo Costa e Silva (2013), cuidar se constitui como um dos exercícios mais antigos do ser humano, desenrolando-se em uma prática de caráter formal/profissional e informal/popular influenciada por questões de gênero - o papel de cuidado é majoritariamente exercido por mulheres - por fatores, sociais, econômicos e culturais de cada época.

Os autores supracitados definem o cuidado como uma necessidade e recurso do ser humano que perpassa as esferas biológicas, psicológicas, espirituais, socioculturais e ecológicas para auxiliar na proteção, recuperação, desenvolvimento, indempentizar e 
criação de novas situações diante dos agravos à saúde, buscando promover o bem-estar e melhorias numa situação de vida, deficiência ou morte. Nas palavras de Amorim (2013, p. 438):

O cuidado inclui, normalmente, duas significações básicas intimamente ligadas entre si. A primeira, a atitude de desvelo, solicitude e de atenção com o outro. A segunda, de preocupação, de inquietação e responsabilidade, porque a pessoa que tem cuidado se sente envolvida e ligada ao outro.

Cuidar envolve processos de troca de sentimentos - sentimentos negativos e positivos - na relação e responsabilidade. Implica em ter intimidade, contato próximo com o modo de ser e de viver do outro. É uma relação de zelo e de desvelo, representando uma atitude de preocupação e de envolvimento afetivo e emocional entre sujeitos (Brasil, 2003; Costa \& Silva, 2013).

Quando discutimos o ato de cuidar, estamos discutindo também a troca de relações e de responsabilidade. Para Mori e Cavalcanti (2017) cuidar de outra pessoa é um processo de troca de experiências, muitas vezes dolorosas, onde o cuidador entra em contato direto com o modo de ser, de viver do outro e de estar no mundo de uma pessoa, convivendo quase que diariamente com os medos, angustias e sofrimentos físicos e não físicos dessa pessoa que precisa de algum cuidado.

De acordo com Campos (2016), o convívio quase que diário com o sofrimento do outro implica em se relacionar com o sofrimento do outro, se identificar com a pessoa que sofre, sentir-se parte do adoecimento e sofrer com ela. Para o autor é impossível que convivamos com o sofrimento do outro e saiamos da situação sem nenhum impacto físico e/ou subjetivo. Assim, a experiência de cuidar tem impacto direto sobre a pessoa que está sendo cuidada e quem cuida.

Em uma pesquisa empírica, Vieira, Fialho, Freitas e Jorge (2010), os familiares 
que assumem os cuidados em uma situação de crise podem sofrer com sintomas psicofísicos como tensão, constrangimento, fadiga, estresse, frustração, diminuição do círculo de relações/convívio, depressão e alteração na autoestima. Além disso, as autoras destacam que os cuidados podem acarretar na diminuição do bem-estar do doente e do cuidador. Por fim, um aspecto que merece ser destacado são os impactos financeiros que a família pode enfrentar durante um processo de adoecimento e cuidado. Entretanto, para seguirmos, é fundamental destacar que, este trabalho não terá como objetivo um diagnóstico de sintomatologia psicopatológicas, mas de expressões do sujeito diante das situações de cuidado.

Fortalecendo essa perspectiva, Campos (2016) aponta que as circunstâncias de vida das pessoas influenciam na forma como elas se relacionarão. Logo, podemos compreender que os momentos de cuidado podem causar tensões, visto que é uma situação de adoecimento e eminencia da morte. Nesse sentido, o cuidar pode ser um fator estressor, podendo impedir que o cuidado seja prestado de forma efetiva, afetiva e digna tanto com a pessoa doente e consigo mesmo. De modo igual, o cuidador pode exceder no cuidado ou sentir raiva.

Há também a possibilidade agravante de que a pessoa que vai exercer o cuidado não tem nenhum preparo físico e emocional para cuidar. Cavalcanti e Mori (2015) a família pode não estar preparada e amparada para enfrentar uma situação de adoecimento físico ou mental de uma pessoa do seu núcleo familiar, o que pode tornar a vivência do adoecimento e de cuidado ainda mais tortuosa e desafiante

Assim, o cuidado mobiliza e facilita diferentes processos subjetivos que marca a forma como essas pessoas - quem cuida e quem é cuidado - se relacional e se configuram. A experiência de cuidar e de ser cuidado tem diferentes significados, variando de pessoa para pessoa e de contexto para contexto. Pra Brasil (2008), cuidar 
de uma pessoa se torna diferente e único, pois, há diferenças históricas e individuais tanto entre os cuidadores como entre as pessoas que recebem cuidado.

O encontro entre o cuidador e a pessoa cuidada sofrerá influência das atuais circunstâncias de vida de ambos:

[...] Se sentir doente carrega um conjunto de significados adquiridos através da vida, desde as primeiras experiências infantis, passando pelas normas, crenças e valores introjetados, que fazem o indivíduo reagir de modo absolutamente pessoal à doença. E, em consequência, ao cuidador. Este, por seu turno, carrega o mesmo conjunto de "impressões" que são singulares, dele, e que, muitas vezes, contrastam com as do paciente. A forma de cuidar (e de receber esse cuidado) sofrerá a influência do conjunto de experiências e crença da dupla, interferindo nos resultados do cuidado oferecido (Campos, 2016, p.28).

O cuidador é a figura de referência para a pessoa doente, e é no processo de cuidado que o cuidador pode se sentir sobrecarregado. A forma como o cuidador lida com seus sentimentos, suas angústias, necessidades e desconfortos provocados no processo de cuidar nos possibilita compreender os aspectos subjetivos configurados nessa experiência. Pois segundo Costa e Silva (2013) o cuidar de alguém representa uma preocupação, responsabilização e um envolvimento emocional com o outro e, em certas situações cuidar de outra pessoa que está doente implica um tipo de relação que muitas vezes sobrecarrega ou implica abrir mão de projetos pessoais em prol do outro. É uma abdicação de si pelo outro.

No meio científico, percebe-se uma ascendência no interesse em estudar e compreender os processos de cuidados e as pessoas envolvidas de forma direta e indireta. Inicialmente investiu- se maciçamente em estudos e projetos para os cuidadores formais e, atualmente, é notável investimentos, mesmo que ainda em baixa escala nos estudos dos cuidadores informais. Justifica-se tais investimentos, pois, é fundamental a reciprocidade no cuidado, salientado que, o cuidador precisa de cuidado, também precisa de cuidado, acolhido, protegido e amparado tanto no cuidado do outro e de si mesmo (Campos, 2016; 
Costa \& Silva, 2013).

O cuidado se configura individual e socialmente, considerando que as experiências individuais se organizam junto aos processos sociais e culturais. Ou seja, os processos subjetivos individuais não se restringem a fenômenos intrapsíquicos, eles se organizam diante da história de vida da pessoa e dos espaços sociais. Desta forma, o ato de cuidar é uma ação social, embrenhada e perpassada por sentidos subjetivos e, estreitamente relacionado com a composição antropossocial na qual o sujeito está inserido. Diante deste enfoque, será discutido o cuidado e seus impactos a partir da visão cultural-histórica, com ênfase na teoria da subjetividade (Cavalcanti \& Mori, 2015; Cavalcanti \& Mori, 2017; Costa, 2015; González Rey, 2011; Mori \& González Rey, 2011).

A teoria da subjetividade representa uma alternativa possível para que as ciências psicológicas e sociais possam compreender de forma complexa o psiquismo humano diante dos seus processos subjetivos individuais e sociais através da produção de inteligibilidade sobre a função e os processos sociais, culturais, simbólicos e afetivos expressos nas relações. A categoria subjetividade é definida como um processo humano, definida através do atributo simbólico-emocional da experiência humana (González Rey, 2011; González Rey, 2015; Goulart, 2015). Dessa forma, a relação de cuidado expressa a organização dos processos subjetivos individuais e sociais das diferentes pessoas que participam desse relacionamento.

Ainda sobre a definição da categoria subjetividade proposta por González Rey, Mori (2015, p. 116):

A categoria subjetividade não é inerente à pessoa, mas à organização processual e sistêmica, integrando diferentes processos que se configuram na experiência da pessoa: individual/social, cognitivo/afetivo, consciente/inconsciente, etc. a subjetividade se define pela natureza dos seus processos, ou seja, a complexa relação do histórico e do qual que constituem os diferentes momentos do homem e do social assim como na forma que adquirem sentido e significado a partir dessa relação. 
É importante refletir sobre os processos subjetivos que estão configurando essa relação e a maneira como a subjetividade social tem implicação para a forma como se vive a experiência do cuidado. Segundo González Rey (2005b) a subjetividade social diz respeito aos elementos subjetivos de cada sujeito que são produzidos nos processos relacionais de grupo ou agências sociais no seu funcionamento atual. Ademais, o autor destaca que essa categoria rompe com a ideia de que a subjetividade é exclusivamente um fenômeno exclusivamente individual, pois a subjetividade tem aspectos da esfera individual e social.

Ora, para González Rey (2011), a subjetividade social garante a emersão da cultura nos processos individuais. Assim, busca-se a integração e a inseparabilidade do emocional e o simbólico nos trabalhos de pesquisa a organização configuracional que impede a redução das esferas de vida da pessoa à psicologizações acríticas e descontextualizadas.

Desse modo, a subjetividade se organiza na forma como as pessoas vivem, cuidam, se alimentam, se comunicam, dividem espaço de convivência, trabalham e convivem. Diante disso, Cavalcanti e Mori (2017), afirmam que a forma como o cuidado pé organizado e executado e as pessoas responsáveis por cuidar de modo prático e/ou oferecer suporte para que o cuidado aconteça vai depender da cultura e do cenário social que essa situação de cuidado está inserida. Para ilustrar, Costa e Silva (2013) afirmam que comumente é dever da mulher cuidar. Cuidar das crianças, do marido, dos filhos, dos familiares acamados e que se preparam para morrer.

De acordo com Vieira (2015), a sociedade no seu processo estrutural desenhou papéis diferentes para homens e mulheres, deixando linhas marcadas do que competia a cada sexo. $\mathrm{O}$ feminino foi construído diante de mitos de amor incondicional e prontidão para o cuidado que qualquer pessoa da sua família e proximidade. Para conservar esse 
dever e fado às mulheres, socialmente se tem mecanismos de controle que vigiam e punem mulheres que fogem à norma.

Os processos emocionais e simbólicos que são mobilizados no cuidado referem-se aos recursos subjetivos das pessoas no viver essa experiência e nos possibilitam compreender os aspectos sociais e históricos que a envolve. Por exemplo, o cuidado é relacionado principalmente com a figura das mulheres, pois tradicionalmente na nossa sociedade ocuparam esse lugar (Vilaça et al, 2005). Essa é uma expressão da subjetividade social dominante da nossa cultura. "São processos da subjetividade social as representações hegemônicas, os sistemas normativos formais ou informais da sociedade, os sistemas discursivos dominantes, a religiosidade e toda forma de institucionalização" (González Rey, 2017, p.88).

Já a subjetividade individual é entendida como a organização das diferentes experiencias de vividas no curso da existência de uma pessoa. Esta categoria atribui a vivência individualizada de cada situação, é a forma como cada produz sentidos subjetivos sobre as formas de vida social. É a integração da história da pessoa, sua história de vida, seus contextos atuais e a expressão de cada sujeito individual e único (González Rey, 2005a/b; Mori e González Rey, 2012).

González (2015) e Mori e González Rey (2012) o sentido subjetivo está intimamente envolvido com a subjetividade individual e social, estando associado à ação do sujeito na ação e na organização da subjetividade individual do sujeito. O sentido subjetivo é integra elementos dos diversos contextos de vida de uma pessoa. Essa é uma categoria responsável por integrar a dimensão simbólica e emocional de forma permanente diante das ações do sujeito. Dito pelos autores, sentido subjetivo é:

É uma produção do sujeito na sua relação com o mundo, tornando a realidade subjetiva, alimentando-se constantemente da experiência vivida, não só as ações do sujeito no momento atual, mas também dos sentidos historicamente configurados nesse sujeito. Não há sentido 
universal, ele se caracteriza como produção singular, pois todo sentido subjetivo traz a marca da história do sujeito e de sua ação nos contextos atuais de sua vida (Mori e González Rey, 2012, p. 146).

É fundamental ressaltar que a subjetividade social e individual são momentos diferentes de um mesmo sistema, de uma mesma vida. A subjetividade é um processo cíclico e em constante mudança e desenvolvimento que se expressam nos sujeitos concretos através de suas manifestações simbólicas, é o enlace entre esses dois sistemas que caracterizam a individualidade de cada sujeito haja visto que todos os sistemas que a pessoa se inseriu e se insere terão significados diferentes que nutem a vida do ser humano (Caixeta, Mori e Bezerra, 2017; Mori \& González Rey, 2011/2012).

Assim, a relação de cuidado está associada a processos de subjetivação do indivíduo, e como a pessoa subjetiva o processo de cuidar, pois cuidar de algo ou alguém são processos singulares que não se organizam de forma padronizada, pois implicam a pessoa a partir de diferentes processos subjetivos mobilizados nessa experiência. Assim, um dos aspectos importantes para o estudo desse processo é reconhecer a organização singular dessa experiência para as diferentes pessoas. Pois a subjetividade não se expressa de forma linear e previsível.

\section{Metodologia}

Este trabalho tem como base a Epistemologia Qualitativa de González Rey e, metodologicamente é representada pelo método construtivo-interpretativo. Tal proposta rompe com o modelo positivista de construção de conhecimentos.

Segundo Goulart (2015), a proposta de González Rey objetiva lançar luz sobre a complexidade do psiquismo a partir da perspectiva histórico-cultural, assumindo como três princípios basilares para o fazer científico:

1) O caráter construtivo-interpretativo do conhecimento compreende o conhecimento como produção humana. Sendo ele um elemento construído de forma 
dinâmica, relacional, não linear e/ou estático (González Rey, 2005b). Complementando, Mori (2015) afirma que, o caráter construtivo-interpretativo coloca o pesquisador como ser capaz de produzir novas zonas de sentido sobre o fenômeno estudado através de aproximação da realidade manifesta durante a pesquisa. Além disso, o pesquisador tem potencialidade produzir novas zonas de sentidos através do embate entre a teoria e o momento empírico. É fundamental destacar que tanto para González Rey (2005b) e Mori (2015) é o papel do investigador estar na pesquisa de forma ativa e participativa e, produzindo novas zonas de sentido.

2) O singular como instância legítima de produção do conhecimento científico; o que implica conceber a pesquisa como produção teórica que se alimenta da principal característica da subjetividade humana, que é a diferenciação marcada dos indivíduos e dos distintos espaços da vida social, cuja significação epistemológica “[...] está estreitamente relacionada ao valor teórico da subjetividade no estudo do homem, a cultura e a sociedade, dimensões que se constituem, de forma permanente entre si” (González Rey, 2005b, p.13). Ao passo em que as hipóteses são elaboradas à posteriori do contato com os casos singulares, estas servem para repensar e recriar o modelo teórico, que assim é capaz de "ampliar tanto suas alternativas de inteligibilidade sobre o estudado como seu permanente aprofundamento em compreender a realidade estudada como sistema” (González Rey, 2005a, p.12).

Destaca-se também que contrapondo ao modelo positivista e quantitativista, aqui a produção de conhecimento não se dá e/ou se legitima pela amostra de pesquisa, mas pela qualidade das expressões dos sujeitos de pesquisa que são manifestas durante todo o processo de pesquisa. De acordo com Mori (2015), é nas subjetividades individuais e únicas que a construção de conhecimento tem potencial para acontecer.

3) Compreender a pesquisa como um processo dialógico, ou seja, a 
comunicação como via privilegiada de construção do conhecimento, através da qual "é possível conhecer configurações e processos de sentido subjetivo que caracterizam os sujeitos individuais e que permitem conhecer o modo como as diversas condições objetivas da vida social afetam o homem” (González Rey, 2005b, p.13).

Mori (2015) destaca que a comunicação é a via de acesso aos processos subjetivos, possibilitando através de um processo dialógico-conversacional não restritivo, rígido e empobrecido. É por meio da comunicação que o conhecimento ganha a possibilidade de ser construído.

Dentro a Epistemologia Qualitativa esses preceitos básicos fornecem para o pesquisador insumos teórico-metodológicos para o entendimento da produção de conhecimento através de indicadores, hipóteses e um modelo teórico explicativo. Desse modo, a pesquisa deve gerar novas zonas de sentidos - novas possibilidades de aprofundamento na produção teórica (Mori, 2015; Reis \& Campolina, 2017).

\section{Instrumentos}

Os instrumentos são usados como estimuladores e provocadores de expressão dos participantes ao longo da pesquisa e devem ser utilizados para estimular a expressão subjetiva dos sujeitos. Se tratando de uma pesquisa qualitativa, o instrumento pode ser uma via de acesso das expressões da pessoa, estimulando a emersão de informações relevantes do sujeito que participa da pesquisa. Ainda, os instrumentos de uma pesquisa podem potencializar a criação de vínculo entre pesquisadores e participantes de pesquisa (González Rey, 2005; Mori, 2015; Reis \& Campolina, 2017).

Para essa pesquisa foram utilizados três instrumentos: 1) o formulário de caracterização de participante (Anexo A), e a 2) dinâmica conversacional.

O formulário de caracterização de participante foi construído especialmente para esta pesquisa, tendo como meta central levantar informações 
características dos participantes da pesquisa tais como: idade, sexo, gênero, religião, escolaridade, parentesco com a pessoa cuidada, tempo de cuidado exercido, motivo do cuidado/tipo de adoecimento, a pessoa cuidada é viva, estado civil, idade da pessoa cuidada, entre outras informações que o participante acredite ser importante adicionar.

A dinâmica conversacional se caracteriza como uma conversaçãoaberta que não se restringe a perguntas diretas e fechadas como na entrevista (González Rey, 2005b) O processo dialógico é peça fundamental para que o conflito de diálogos aconteça. A participação de todos é fundamental para que o diálogo aconteça e que os sujeitos se expressem, sendo que o dever do pesquisador facilitar o processo de comunicação, promover relações e se envolver com o processo de forma ativa e participativa, não sendo mero expectador do que é falado. O processo de comunicação compromissada da díade pesquisador-pesquisando cria espaços relacionais para a produção de informações e o aparecimento de sentidos subjetivos (González Rey, 2005b).

Diferente do modelo de entrevista, que até então centrava a atenção do pesquisador na preparação a priori das questões que seriam feitas dentro de um caráter quase que puramente instrumental. A conversação/dialogicidade se caracteriza pela processualidade da relação entre pesquisador e participante da pesquisa, dando espaço para que a pessoa se expresse da sua forma, dentro do seu tempo e nos seus limites relacionais (Mori \& González Rey, 2011).

\section{Participantes}

Participou deste estudo uma mulher de 46 anos (aqui o nome fictício será Rosa), com ensino médio completo, evangélica que cuidava do marido de 48 anos que em 2017 iniciou o tratamento para interromper o vício em drogas e em 2018 foi diagnosticado com 
esquizofrenia.

\section{Procedimentos éticos}

Para a aplicação dos instrumentos, a pesquisa foi aprovada pelo Comitê de Ética e Pesquisa com Seres Humanos do Centro Universitário de Brasília (CEP / UniCEUB) sob o parecer de número 2.649.329 e CAAE 88069118.1.0000.0023.

\section{Cenário social e local da pesquisa}

De acordo com Reis e Campolina (2017) o cenário social da pesquisa é uma esfera de fundamental importância numa pesquisa, impactando direta ou indiretamente no processo de construção da informação. Um cenário social pode favorecer a criação dos vínculos entre todos os envolvidos na pesquisa, devendo ser um ambiente facilitador das expressões da pessoa.

As mesmas autoras consideram que os diferentes momentos da pesquisa devem ser conduzidos pelo pesquisador de modo cuidadoso e ético. Tendo sempre em vista a criação de um tablado para que os participantes e o próprio pesquisador narrem suas histórias, exponham seus sentimentos, seus sonhos e vontades. Contudo, a entrega na expressão autentica deve ser estimulada sempre.

Rossato, Martins e Mitjáns Martínez (2014, citadas por Reis \& Campolina, 2017) reiteram que o propósito do cenário da pesquisa é a construção de um "espaço" relacional entre os atores da pesquisa, sendo que o sucesso do cenário social da pesquisa dependerá do vínculo estabelecido entre todos e a capacidade do pesquisador de contornar possíveis dificuldades que possam fragilizar ou romper com o vínculo.

Diante de tais apontamentos e do cuidado necessário para a condução de uma pesquisa onde inviavelmente se teve a possibilidade da exposição algum tipo de 
sofrimento e de conteúdos da vivência dos participantes de pesquisa os pesquisadores compreenderam a necessidade de criar não somente ambientes físicos facilitadores de comunicações e relações, mas também de postura e entrega ao trabalho.

À vista disso, abaixo segue o detalhamento de como se deu o passo-a-passo do momento empírico. Destacamos que esse modelo funcionamento não estava pronto de antemão, mas foi criado durante do desenrolar da pesquisa e construção das relações e vínculos.

Foi feito o contato por telefone com o sobrinho da participante, o qual se responsabilizou por marcar o momento do encontro com o pesquisador. Foi marcado o momento do encontro, mas teve que ser remarcado incialmente por necessidade da participante.

A aplicação dos instrumentos foi feita na casa da cunhada de Rosa, teve duração aproximada de duas horas desde o contato inicial, até o encerramento oficial, o pesquisador inicialmente apresentou o Termo de Consentimento Livre e Esclarecid (TCLE - Anexo B), leu junto com a participante, perguntou se tinha alguma dúvida, solicitou a assinatura das duas vias do comumente, assinou também e deixou uma via com a participante, depois disso, deu-se início à conversação. No final, o pesquisador agradeceu as contribuições da participante e de despediu.

Ao final o pesquisador recolherá o complemento de frase, agradecerá novamente a participação da pessoa na pesquisa e se disponibilizará a passar o relatório da pesquisa após a análise e construção da informação para cada participante, se assim for da sua vontade.

\section{Aspectos teóricos para a construção e análise das informações}

Perante a Epistemologia Qualitativa e o método construtivo interpretativo a construção e análise das informações que emergem durante o desenvolver da pesquisa vai 
na contramão da neutralidade e isenção do pesquisador diante do desenrolar da pesquisa. Nessa seção, é fundamental o caráter interpretativo do pesquisador. González Rey (2005b) afirma que o processo interpretativo é motriz para que o pesquisador crie hipótese e posteriormente, processos de inteligibilidade sobre o fenômeno estudado.

Nas palavras de Mori (2015) a construção da informação tem forte e intima ligação com a capacidade interpretativa e de articulação do pesquisador, exigindo que ele construa diversificadas informações sobre a sua pesquisa, integrando o momento empírico, indicadores, hipóteses e o modelo teórico de base. Para a autora, a interpretação é marco de referência para que o pesquisador possa compreender seu objeto de estudo.

Reis e Campolina (2017) destacam que as hipóteses compõem uma pesquisa não para comprovar a existência de algo, mas sim, como questionamentos e conjunturas em que o pesquisador pensa a respeito da pesquisa e do seu momento empírico através das manifestações e expressões do participante da pesquisa e, posteriormente se levanta as hipóteses.

Segundo Goulart (2017), os indicadores, dentro da Epistemologia Qualitativa se constituem como "matérias-primas" para a construção do escopo teórico e de inteligibilidade da pesquisa. Para o autor, um indicador pode ser expresso pelo sujeito das mais diversas formas, podendo, se mostrar de forma translucida ou mais neutra, não tendo uma forma linear e expressão única, sua qualidade dependerá da construção interpretativa daquele que está observando.

Logo, o pesquisador é um aventureiro, responsável por estar atento a cada aspecto da floresta que está explorando. Prestar atenção em tudo é primordial, cada manifestação da individualidade e da subjetividade deve ser vista com admiração e respeito. Para Goulart (2017) a articulação de diferentes indicadores viável a elaboração de hipóteses mais amplas e consistentes, o que desembocará num modelo teórico. 


\section{Construção e análise das informações}

Iniciaremos esta seção do trabalho de modo a ressaltar uma característica percebido nesta pesquisa e em parte do referencial bibliográfico usado para refletir, discutir e escrever sobre as vivências que perpassam a experiência de ser cuidador. Diante disso e em concordância com Costa e Silva (2013) reconhecemos que as práticas de cuidado de modo geral sofrem interferência direta de fatores sociais, culturais e econômicos, entretanto, vale destacar que quando o cuidado é desempenhado de modo informal, há de se ressaltar que essa afirmativa ganha tons mais fortes e se torna muito mais evidente, principalmente por ser o cuidado uma atividade quase que exclusiva das mulheres, visto que a sociedade impõe a elas, como parte da sua performance de gênero o cuidar, independente de quem seja e do significado que essa pessoa teve na vida dessa mulher, ela deve seguir cuidado, mesmo que lhe cause alguma sobrecarga ou adoecimento.

Destacaremos abaixo conteúdos aqui relevantes da fala da participante para que possamos discutir com articulações teóricas e empíricas suas produções frente o adoecimento do marido e ser cuidadora, presença das construções sociais delimitando quem deve exercer papel de cuidadora e as tensões e construções de Rosa frente a essas duas esferas.

No cenário inicial a participante se limitava a falar somente sobre o marido e das necessidades dele. Sua fala inicialmente era desorganizada, imprecisa, sem uma lógica e coerência temporal para quem observava, contudo, após algum tempo de conversa Rosa começou a expressar-se de modo mais organizado e coeso.

Desde o contato inicial para a condução da dinâmica conversacional ficou evidente na concepção do pesquisador que Rosa demonstrava necessidade de um espaço para se expressar enquanto pessoa, enquanto ser humano de necessidades específicas e individuais, sendo esse um indicador presente em diferentes momentos da fala da participante e em diferentes relações. Como pode ser visto a seguir: 
- Agora ele está uma pessoa fechada, agora ele tá assim. Não sei se é por conta dos remédios ele está mais calado, mais fechado, sem comunicação, nem nada. Eu chego do trabalho perguntando como que foi o dia dele, as vezes eu fico falando do meu dia, quero falar sobre alguma coisa. Mas ele, não liga! Fica lá na TV com o volume baixo. Tem vezes que eu vou falar e ele pede para eu falar baixo com ele, ele mudou.

Este trecho de diálogo evidencia a necessidade que a participante tem de ter um contato mais próximo com o marido, de compartilhar a sua rotina e os acontecimentos do seu dia, além disso, ela tem desejo de saber da rotina do conjugue, evidenciando assim que para Rosa, o espaço de escuta e conversar tem valor significativo. Ademais, por se tratar do marido, nota-se uma produção subjetiva da participante frente ao silencio do marido, mesmo tendo conhecimento objetivo de que o uso das medicações para controle dos delírios e alucinações interfere na qualidade das interações que o marido estabelece com o mundo, Rosa se sente desassistida pelo companheiro, não vista na relação.

- "Cheguei aqui já conversando com a Joana, assim, falando as coisas né. Conversando, porque não tenho com quem conversar, me falta esse espaço”.

Esse trecho traz um apontamento interessante visto que Rosa na relação com o marido mesmo sentindo a necessidade de ter um espaço de diálogo com o marido o que na maioria das vezes não se consuma, o que faz com que, em determinados espaço e relações, ela expresse suas necessidades, visto que esse trecho aponta um indicador significativo, que é o sentimento de falta de espaço nas relações. Contudo, mesmo diante desse sentimento, Rosa não paralisa, visto que continua produzindo sentidos sobre tal falta de espaço. Este indicador corrobora com o escrito de Mori (2015) que considera a comunicação como um espaço 
importante das relações humanas, pois, é através dela que temos a possibilidade de compartilhar com os outros, expressarmos nossas necessidades e organizarmos de modo mais ativo nossas vivências.

Diante de uma fala inicialmente desorganizada Rosa foi exteriorizando o quão os dias atuais estavam sendo demarcado pela presença de emoções negativas que lhe causava algum mal-estar diante da postura de cuidadora. Os trechos abaixo ilustram esse processo:

- Aí, alguma coisa está acontecendo que eu não estou entendendo. Eu não estudei isso! Como é que eu vou saber?

- E ver tudo agora, depois que todas as preocupações saíram, saiu tudo né?

- Agora ele está voltando para casa e eu vou ficar vendo onde o barco vai, mas eu vou estar sozinha, não sei que remédio tomar para me aliviar.

Os trechos compartilham a expressão de sentimento da participante, sendo considerado um indicador de sentimento de incapacidade, incerteza e impotência diante do exercício do cuidado que Rosa dispensa para o marido. Ainda sobre aspectos da emocionalidade de Rosa frente ao cuidado a solidão foi discutida como constante. Destaca também a questão da sensação de insuficiência e impossibilidade da participante de dar o suporte mínimo que o companheiro precisa para ter uma boa vida diante do seu adoecimento, mas com foco total na doença. Tal indicador ilustra o como é comum, ao tratarmos de um adoecimento, todo o cuidado ser voltado para a doença, ignorando qualquer outra característica e necessidade do sujeito, as necessidades dele acabam se resumindo ao que o diagnóstico diz ser dele. Este é um discurso dominante e pode ser classificado como parte da subjetividade social. Vale destacar que essa última parte da fala da participante evidencia parte dos discursos sociais compartilhados e que aqui nomeados de subjetividade social 
(González Rey, 2005b) que é a da medicalização da vida.

Como indicado na fala da participante, é válido apontar que o adoecimento é uma situação que reverbera na vida de quem adoece e também, na vida de indivíduos que convivem direta ou indiretamente com essa pessoa. E no caso de quem cuida, os abalos, incômodos e perturbações podem ser mais diretos e afetar de forma significativa a vida dessa pessoa. Campos (2016) e Mori e Cavalcante (2017) corroboram com essa hipótese ao afirmarem que para que o cuidado aconteça é preciso se relacionar com a pessoa que necessita do cuidado e diante dessa troca de experiências que a relação proporciona, o cuidador experimenta sensações dolorosas de sofrimento físico e não físico que podem desembocar em processos subjetivos e físicos de quem cuida.

Tornar-se cuidador pode gerar no indivíduo muitos sentimentos e emoções que em muitos casos conflitam com o que é socialmente esperado. Constantemente associamos que a pessoa que cuida tem total responsabilidade sobre a que está sendo cuidada e que além disso, ela tem todas as respostas e reconhecem todas as necessidades de que está doente. Assim, se trata do modo como as pessoas vivenciam as experiências de cuidado frente ao que é socialmente esperado, ou seja, é um momento de choque entre a subjetividade social e invisual (González Rey, 2011). Em algumas situações as produções dos cuidadores se expressam através de um adoecimento emocional e/ou físico. Foi visto que frente a postura de cuidadora, de ser a principal e quase que única responsável pelos cuidados com o marido, Rosa demonstra desgaste emocional e físico.

- "Eu estava sentindo muita dor de cabeça, depois comecei a sentir dor nas pernas e em seguida cãibras numa perna. Não sei se era de muito caminhar, de fazer muito alguma coisa, ou eu que não tinha descoberto isso ainda”.

- É no dia a dia que o cansaço físico vem, que vem as dores de alguma região 


\section{[do corpo].}

O trecho anteriormente apresentado revela um importante indicado para o adoecimento de Rosa, a sobrecarga/excesso de funções que a mesma exercia e exerce. $\mathrm{Na}$ rotina da participante é perceptível que ela desempenha para além da função de cuidadora, a de provedora da casa dentre outras muitas, as quais exigem dedicação temporal e pessoal, o que pode estar levando para um processo de esquecer-se de si, das suas necessidades físicas e emocionais. Logo, como uma das características e produções subjetivas da participante foi a de se colocar em um lugar ser de menos valia, onde as suas necessidades eram atendidas minimamente e em certas situações se tinha um total dispensa desse suprimento básico afetivo e físico.

As produções individuais frente ao cuidado diz sobre cada indivíduo, no caso de Rosa, é notável um conflito com os papéis de gênero construídos socialmente. A fala seguinte ilustra muito bem este indicador:

- Como cuidar de mim e da casa? Como ser o homem e a mulher? Como é que eu estou?

O conflito que Rosa vivencia tem relação com aspectos da subjetividade social dominante que define que é o homem que tem o dever de prover, cuidar da sua mulher e da sua casa, garantindo a subsistência de família. Ou seja, esse são processos sociais que são integram a produção de cada sujeito dentro de uma característica da cultura (González Rey, 2011), que ao ser rompida, invertida e/ou acumulada a performance de gênero pode causar desconforto e incoerência, visto que as características de gênero são ensinadas desde a infância e cobrada desde então. confusão na performance dos papéis de gênero definido 
dentro de um processo histórico.

O conflito experimentado pela participante vem do choque que ela vivencia entre o que ela foi preparada para fazer - cuidar da casa, do marido, dos filhos, ser uma boa dona de casa. Contudo, com o adoecimento ela passa a acumular as "tarefas do homem" - trabalhar, prover o sustento da casa, não expressar emoções, tomar decisões -, além do conflito, é notório que esse acumulo de atividades desempenhadas por Rosa tem lhe causado uma grande sobrecarga e desgaste emocional e físico.

No que tange a família, esta se mostrou presente no discurso da participante, no entanto, sem participação e suporte ativo, responsabilizado e impondo quase que totalmente Rosa para exercer o cuidado e tomar as mais diversas decisões sobre as terapêuticas adotadas e a vida do marido. Os trechos a seguir ilustrarão e discutirão esse processo impactando a vida de Rosa e o desempenho do cuidado com o marido:

- Cheguei a falar com a Joana que é irmã e com a mãe dele. Cheguei na família e falei: ele é meu marido, meu esposo, mas não posso definir nada para ele, essas decisões é coisa da família e é ela que tem que tomar uma atitude. Aí eles me falaram que quem estava com ele era eu, então, eu que tinha que decidir e saber o que fazer.

- Eles diziam: é você quem tem que decidir, é você que tem que fazer. E eu achava que quem tinha que fazer era a família. Eu achava que a família tinha que decidir, a família tinha que pegar e fazer.

- Eu não dormia, as vezes conseguia cochilo, mas ele se levantava, ficava conversando, andando pela casa toda e saia para fora com uma faca. $\boldsymbol{E}$ ninguém definia nada. 
A família delegava todas as responsabilidades para Rosa, o que a sobrecarregava ainda mais. Na conversação com a participante, pode ser observado o não dito como: já não bastava eu cuidar dele, vocês ainda querem que eu decida sobre o que fazer? O que para ela era muito difícil e ela sentia que não tinha com quem contar, para quem gritar por ajuda. Tomar decisões não era fácil visto que para ela era algo muito impactante internar ou não o marido em um hospital psiquiátrico. Aqui, temos um indicador sobre a postura inativa da família frente ao cuidado e a busca de Rosa para ser escutada, vista e amparada.

E diante de tantas delegações e de todos os conflitos relacionados aos papéis que ela vinha desempenhando, à percepção que sua vida corria risco em algumas situações já que morava sozinha com o marido e este já tinha surtos psicóticos violentos quase que diariamente Rosa adota um papel ativo no processo.

O destaque da fala da participante retrata muito bem a mudança na postura de Rosa:

- Mas muitas das vezes falaram com permissão: você que tá com ele, você que tem que decidir internar.

Evidente que o processo de atives de Rosa não aconteceu de um dia para o outro, foi uma construção diante dos diversos desafios que ela vinha enfrentando e posterior a isso, ela começou a construir novas possibilidades, ser sujeito ativo no processo, olhar para si e suas necessidades. Além disso, Rosa buscou compartilhar todo o seu processo com os familiares do marido, incluindo-os e os tornando presente nas suas decisões, como pode ser ilustrado pelo momento em que ela decide internar o marido:

- Tudo o que eu tentava perceber foi onde eu passei ver que realmente tinha que internar ele. Mas eu sozinha? Lá na minha casa? Então eu vim procurar socorro ao lado da família dele. Ligue para a ambulância! 
- Hoje não dá mais! O limite acabou, tinha que internar ele naquele dia. Eu tinha que fazer as coisas!

- Ele podia machucar a gente, ele mesmo. Tinha que ver alguma coisa para ajudar ele, tomar uma atitude.

E no momento que Rosa decide internar o marido, a fala dela ilustra uma postura de se reconhecer, de reconhecer suas necessidades enquanto pessoa:

Eu não tava conseguindo mais com ele

\author{
Considerações Finais
}

\title{
Cronograma
}

\begin{tabular}{|c|l|l|l|l|l|l|}
\hline $\begin{array}{c}\text { Período/ } \\
\text { Atividades }\end{array}$ & Mar & Abr & Mai & Jun & Jul & Ago \\
\hline $\begin{array}{c}\text { Submissão ao } \\
\text { Comitê de Ética }\end{array}$ & & & & & & \\
\hline $\begin{array}{c}\text { Recrutamento e } \\
\text { seleção dos } \\
\text { participantes }\end{array}$ & & & & & & \\
\hline $\begin{array}{c}\text { Aplicação dos } \\
\text { instrumentos }\end{array}$ & & & & & & \\
\hline $\begin{array}{c}\text { Construção das } \\
\text { informações }\end{array}$ & & & & & & \\
\hline $\begin{array}{c}\text { Construção do } \\
\text { relatório final }\end{array}$ & & & & & & \\
\hline $\begin{array}{c}\text { Correção do } \\
\text { relatório final }\end{array}$ & & & & & & \\
\hline $\begin{array}{c}\text { Entrega do } \\
\text { relatório final }\end{array}$ & & & & & & \\
\hline
\end{tabular}




\section{Referências}

Brasil. (2003). Cuidando de quem cuida: manual para quem cuida de uma pessoa que precisa de cuidados permanentes. Serviço de atenção comunitária. Porto Alegre. Rio Grande do Sul.

(2008). Cuidar melhor e evitar a violência: manual do cuidador da

pessoa idosa. Secretaria Especial dos Direitos Humanos. Brasília. Distrito Federal.

Campos, E.P. (2016). Quem cuida do cuidador? Uma proposta para os profissionais de saúde.

Editora Unifeso: Teresópolis e Editora Pontocom: São Paulo. $2^{\circ}$ Edição.

Caixeta, T., Mori, V.D., \& Bezerra, M.S. (2017). A teoria da subjetividade no estudo de dependência química: refletindo além das práticas excludentes. Investigação Qualitativa em Saúde.

Cavalcanti, B.S. \& Mori, V.D. (2015). Análise de processos subjetivos na relação de cuidado entre familiares. Monografia. Centro Universitário de Brasília.

Cavalcanti, B.S. \& Mori, V.D. (2015). Análise de processos subjetivos na relação de cuidado entre familiares. Revista Katharsis. N.23.p.60-69.

Costa, I. I. \& Silva, E. A. (2013). Dores dos “cuida-dores” em saúde mental. Dissertação de mestrado. Universidade de Brasília.

Costa, J.M. (2015). Educação física e saúde: notas para um diálogo com a teoria da subjetividade numa perspectiva histórico-cultural. In. González Rey, F.L. \& Bizerril, J. (2015). Saúde, cultura e subjetividade: uma referência interdisciplinar. Brasília:

\section{UniCEUB.}

González Rey, F.L. (2005a). Sujeito e subjetividade. São Paulo: Pioneira Thomson Learning. (2005b). Pesquisa Qualitativa e Subjetividade: os processos de

construção da informação. São Paulo: Pioneira Thomson Learning. (2011). Subjetividade e Saúde: superando a clínica da patologia. São 
Paulo: Cortez.

(2015). A saúde como trama complexa da cultura, das instituições e da

subjetividade. In. González Rey, F.L. \& Bizerril, J. (2015). Saúde, cultura e

subjetividade: uma referência interdisciplinar. Brasília: UniCEUB.

(2017). Psicologia, Educação e Aprendizagem escolar: avançando na

contribuição da leitura cultural-histórica. São Paulo: Cortez.

Goulart, D.M. (2015). Clínica, subjetividade e educação: uma integração teórica alternativa para forjar uma ética do sujeito no campo da saúde mental. In. González Rey, F.L. \& Bizerril, J. (2015). Saúde, cultura e subjetividade: uma referência interdisciplinar. Brasília: UniCEUB.

(2017). Educação, saúde e desenvolvimento subjetivo: da patologização da vida à ética do sujeito. Tese de doutorado. Universidade de Brasília.

Mori, V.D. (2015). Os sentidos subjetivos configurados na experiência do câncer: um estudo de caso. In. González Rey, F.L. \& Bizerril, J. (2015). Saúde, cultura e subjetividade: uma referência interdisciplinar. Brasília: UniCEUB.

Mori, V.D. \& González Rey, F.L. (2011). Reflexões sobre o social e o individual na experiência do câncer. Psicologia e Sociedade. 99-108.

Mori, V.D. \& González Rey, F.L. (2012). A saúde como processo subjetivo: uma reflexão necessária. Psicologia: Teoria e Prática, v. 14, n. 3, p. 140-152.

Vilaça, C.M., Barreiros, D.S., Galli, F.A., Borçari, I.T., Andrade, L.F., Goulart, M.A., Conceição., C.L. \& Carneiro, M.L.M. (2005). O autocuidado de cuidadores informais em domicilio- percepção de acadêmicos de enfermagem. Revista Eletrônica de Enfermagem,07(02), 221-226

Reis, T.J. \& Campolina. L.O. (2017). O que pensam os estudantes universitários sobre a aprendizagem? Um estudo de estratégias inovadores. Relatório de Iniciação 
Científica. Centro Universitário de Brasília (UniCEUB). 
Anexo A - O formulário de caracterização de participante

Nome:

Sexo: Masculino ( ) Feminino ( ) Idade:

Religião:

Escolaridade:

Estado civil:

Tempo de cuidado:

Parentesco com a pessoa cuidada:

Motivo do cuidado:

Recebeu ajuda de alguém para exercer o cuidado: Sim ( ) Não ( )

Caso sim, de quem?

A pessoa cuidada está viva: Sim ( ) Não ( )

Deseja complementar com outras informações? 


\title{
Anexo B - Termo de Consentimento Livre e Esclarecido
}

\author{
As experiências de ser cuidador: Uma análise de processos subjetivos individuais \\ e sociais \\ Instituição dos pesquisadores: Centro Universitário de Brasília - UniCEUB \\ Pesquisadora responsável: Valéria Deusdará Mori \\ Pesquisador assistente: Gustavo Andrade-Jesus
}

Você está sendo convidada/convidado a participar da pesquisa "As experiências de ser cuidador: Uma análise de processos subjetivos individuais e sociais". O documento abaixo contém todas as informações necessárias sobre a pesquisa da qual você tomará parte. Sua colaboração neste estudo será de muita importância, mas caso sinta vontade de desistir, em qualquer momento será respeitada a sua vontade, sendo garantido que você não sofrerá nenhum prejuízo ou dano.

O nome deste documento que você está lendo é Termo de Consentimento Livre e Esclarecido (TCLE). Antes de decidir se deseja participar desse estudo de livre e espontânea vontade você deverá ler e compreender todo o conteúdo ex posto aqui. Ao final, caso decida participar, você deverá assinar as duas vias deste documento, sendo que uma cópia é sua e a outro dos pesquisadores. Você poderá esclarecer dúvidas quanto a sua participação e da relevância durante todo o processo da pesquisa. A equipe de pesquisadores estará sempre disponível para tais esclarecimentos.

\section{Natureza e objetivos do estudo}

- $\quad$ Compreender os processos subjetivos individuais e sociais na relação de cuidado com o outro.

- Você está sendo convidado a participar exatamente por poder contribuir de forma significativa para esse estudo.

\section{Procedimentos do estudo}

- Sua participação consiste em completar, diante das suas percepções e considerações um formulário de caracterização de participante, complemento de frases e uma dinâmica de grupo.

- $\quad$ Não haverá nenhuma outra forma de envolvimento ou comprometimento neste estudo.

- $\quad$ Será feita gravação de áudio para garantir a fidedignidade da fala dos participantes, mas antes do início das gravações, todos do grupo serão avisados.

\section{Riscos e benefícios}

- $\quad$ Este estudo possui "risco mínimo" que são inerentes do procedimento de coleta de dados por meio de questionários.

- $\quad$ Medidas preventivas durante a aplicação dos questionários serão tomadas para minimizar qualquer risco ou incômodo.

- $\quad$ Caso esse procedimento possa gerar algum tipo de constrangimento você não precisa realizá-lo.

- Sua participação poderá ajudar no maior conhecimento e compreensão das repercussões de cuidar e das configurações subjetivas individuais e sociais nos cuidadores.

Participação, recusa e direito de se retirar do estudo

- Sua participação é voluntária. Você não terá nenhum prejuízo se não quiser participar. 
- Você poderá se retirar desta pesquisa a qualquer momento, bastando para isso entrar em contato com um dos pesquisadores responsáveis.

- $\quad$ Conforme previsto pelas normas brasileiras de pesquisa com a participação de seres humanos você não receberá nenhum tipo de compensação financeira pela sua participação neste estudo.

\title{
Confidencialidade
}

- $\quad$ Seus dados serão manuseados somente pelos pesquisadores e não será permitido o acesso a outras pessoas.

- O material com as suas informações tais como o questionário sociodemográfico, complemento de frases e dinâmica de grupo sob a responsabilidade da Dra. Valéria Deusdará Mori, responsável por essa pesquisa com a garantia de manutenção do sigilo e confidencialidade. Os dados e instrumentos utilizados ficarão arquivados com a pesquisadora responsável por um período de 5 anos, após esse tempo serão destruídos, garantindo a impossibilidade sua identificação.

- Os resultados deste trabalho poderão ser apresentados em encontros ou revistas científicas, entretanto, ele mostrará apenas os resultados obtidos como um todo, sem revelar seu nome ou qualquer outra característica que possibilite sua identificação.

Se houver alguma consideração ou dúvida referente aos aspectos éticos da pesquisa, entre em contato com o Comitê de Ética em Pesquisa do Centro Universitário de Brasília (UniCEUB), que aprovou esta pesquisa, pelo telefone (61) 3966-1490.Também entre em contato para informar ocorrências irregulares ou danosas durante a sua participação no estudo.

$\mathrm{Eu}$, $\mathrm{RG}$ após receber uma explicação completa dos objetivos do estudo e dos procedimentos envolvidos concordo voluntariamente em fazer parte deste estudo.

Brasília, de de

Participante

Dra. Valéria Desdará Mori - pesquisadora responsável

Telefone institucional: (61) 3966-1460

e-mail: mori.valéria@gmail.com

\author{
Gustavo Andrade-Jesus - pesquisa assistente \\ Celular: (61) 98187-8791 \\ e-mail: gustavoandradejesus@gmail.com
}




\section{Endereço dos responsáveis pela pesquisa:}

Instituição: Centro Universitário de Brasília - UniCEUB

Endereço: SEPN 707/907 Asa Norte

Complemento: Faculdade de Ciências da Educação e Saúde - FACES - Bloco 09.

Bairro: Asa Norte Cidade: Brasília - DF CEP: 70.790-075

Telefones para contato: 3966-1490 
